\title{
Curriculum Integration in Chemical Engineering Education at the Université de Sherbrooke
}

\author{
Nicolas Abatzoglou and Maher Boulos \\ Department of Chemical Engineering, Université de Sherbrooke \\ 2500 Boul. Université, Sherbrooke, Québec, Canada, J1K 2R1 \\ Nicolas.Abatzoglou@USherbrooke.ca \\ Maher.Boulos@USherbrooke.ca
}

\begin{abstract}
In this paper the authors present a short description of the first two levels of the Chemical Engineering curriculum integration at the Université de Sherbrooke, followed by a more comprehensive presentation of the Final year Design project course, a 10 credits activity. This activity is already 12 years old. Its main ambition and objectives were and are to integrate all knowledge acquired by the students through the "8 academic +5 industry work training" sessions. Such integration brings the Chemical Engineering graduates closer to the market reality and needs by opening their minds "outside the box" and improving their creative skills and innovation desires. The echo received so far is very positive and the effort, qualified as successful by our industrial partners, provides us all with the necessary motivation to continue in this direction and improve, by remaining as creative as possible. The intermediate integration level in years 2 and 3 is the fruit of this motivation.
\end{abstract}

\section{Introduction}

Almost all reforms in engineering education programs are based on knowledge integration and the development of tools allowing students to acquire a global picture of their professional fields. The development of skills is pursued by means of students' participation in projects designed to be as close as possible to the "real world" in professional practice. The new program of Chemical Engineering at the Université de Sherbrooke includes three levels of integration. The first level is undertaken within the introductory sessions. The students of the two initial sessions $(\mathrm{S} 1+\mathrm{S} 2)$ are launched from their classrooms to "discover" a professional theme, accompanied by a work of definition, and sometimes a small-scale project of industrial production or resolution of a problem, as close as possible to existing market realities.

The students of the two final sessions $(\mathrm{S} 7+\mathrm{S} 8)$ participate, within the framework of their course in Chemical Processes Design, in a design effort, lasting approximately 12 months, during which they are "teamed up" to form working groups with similar structure to those found in companies operating in Chemical Engineering fields. Each student group studies a selected theme or topic, evaluates its feasibility, proposes a production facility that meets a particular need, and undertakes all of the tasks leading to the preliminary engineering of the project.

In the new program an intermediate level of integration in session four, end of $2^{\text {nd }}$ year, (S4) was added, during which the students, in possession of sufficient knowledge of the reaction systems and unit operations, study a module of production and define its details. The S4 integration is aimed at improving the efficiency of the overall educational effort by preparing the students for their final integration within the final two sessions $(\mathrm{S} 7+\mathrm{S} 8)$.

One of the biggest challenges in the evolution of chemical engineering education over the past few decades has been in the passage from the teaching of well focused, and stand alone, courses, to the integration of knowledge into a coherent engineering discipline. Far more often we have observed that our students can excell in the solution of individual problems in unit operations, transport phenomena or reactor design, only to be bogged down with the handling of a problem that is ill-defined or that requires an imaginative solution. The challenge is accentuated in the Chemical Engineering Process Design course where the students are asked to develop their problem solving skills in a completely new environment where economics and engineering science goes hand in hand, and safety and hazard 
analysis are of prime importance. In this paper we describe a series of experiment and curriculum modifications that were conducted at the department of chemical engineering of the Universite de Sherbrooke over the past ten years, where knowledge integration has been of prime concern. Specifically, the work conducted was at three distinct levels in our four and a half year chemical engineering curriculum;

- First year engineering initiation courses $(\mathrm{S} 1+\mathrm{S} 2)$;

- Second-Third years integration courses, and (S4);

- Final year process design courses (S7+S8).

In each of these three levels, curriculum modification aimed at stimulating the interest of the students for the integration of knowledge and making the link between their mathematics \& thermodynamics courses, reactor design, unit operations, materials and process control. The step was not easy but the objective certainly worth while since the curriculum modification aimed at preparing the students to the real life of the practicing chemical engineering who spends most of his or her time dealing with integrated problems which are not necessarily of purely technical nature but often involve social, economic elements and even political and ethical issues.

Although this paper focuses on the final year process design course, a short description of the first two levels will be provided in order to better understand the context of the educational endeavor at the department of Chemical Engineering at the Université de Sherbrooke.

\section{First year engineering initiation project}

Since their first year the students at the department of Chemical Engineering are called to participate in a knowledge integration project. This project brings forward some elements which are basic in the Chemical Engineer profession with the objective of placing the junior students in a context of open problems situation. The students understand rapidly that it is not enough to master the content of a specific course and be successful in solving the well defined problems. In real-life situation, they face opensolution problems, often requiring additional knowledge, both scientific and technical, and a great deal of creativity. The experience from this step is very rich and can constitute a topic of another paper by itself. At this point it is worth mentioning that the basic elements worked out, and with whom the student becomes familiar until the end of the first year project, include:

- The basic concept of the process and its operational modules;

- The need of an open-minded approach leading to high level of innovation potential;
- The principle of the sustainable development;

- The managerial skills required for the good organization and in-time achievement of the project;

- The team work;

- The importance of collaboration and exchanging information with the non-academic sector (companies, organizations, institutions and government/public services at all levels);

- The importance of the socio-economic and sometimes political aspects of the project.

\section{Second and third year integration project}

In this project, starting at Session 4 and finalized at the beginning of Session 5, the students, in possession of sufficient knowledge of the reaction systems and unit operations, study a given module of production and define its details. This integration is aimed at improving the efficiency of the overall educational effort by preparing the students for their final year process design integration course. This project requires an active involvement of all the professors in charge of the teaching of the five courses of given in session 4. Every year the professors choose an existing industrial unit and they analyze it with the students in the classroom. From this industrial unit, 6-7 modules are chosen for detailed study. These could be reactors or a wide range of unit operations. Every chosen module represents an independent expanded homework to be completed by a group of maximum four students. The deliverables include detailed design calculation of the units, set-up of specifications, choice of the most appropriate technologies and materials of construction and cost evaluation.

This project is now three years old and benefited a small financial aid from the University authorities. The approach led so far to the creation of a platform detailing the different stages of chemical engineering process equipment design and a structured list of the existing technologies in each operational module (see an example in Appendix 2). Moreover, a data bank was created providing useful information on available design methods per category and technology and information sources, including books, manufacturers, Internet links and reports. The user is able to better visualize the needs, find the necessary information sources and then perform the tasks.

\section{Final year process design courses}

In the final year design course, knowledge integration is achieved by asking the students to work as a team to solve a complex chemical engineering 
problem of plant design. The students are required to submit by the end of a two-semester course a complete solution of a plant design problem involving either the modification of an existing facility or the development of a completely new project. The work, which was carried out in teams of nine up to twenty students or more, involves the following steps:

- Market study to identify the economic and technical context of the projects and the principal challenges ahead;

- Technology outreach identifying the alternate technological solutions available and options to be considered;

- Process flow diagram;

- Process simulation and dimensioning of the principal equipments;

- Safety and hazard analysis (HAZOP);

- Environmental impact study;

- Site selection and a study of the associated social impact;

- Contact with potential suppliers of the process equipments;

- Process economic study;

- Evaluation of the capital required and the return on investment;

- Economic sensitivity analysis.

Each of these tasks was carried out by a separate subgroup within the overall design team. Often each individual student was asked to participate in the activity of more than one subgroup. The role of individual student also evolved through out the session depending on the needs of the individual subgroups and tasks to be completed.

The method begins with the definition of the generic stages of "Process Design" in Chemical Engineering (see Appendix 1). Thereafter, each stage is detailed and programming of the actions is schematized through the use of commercial software. This schematization is accompanied by data-gathering links allowing the user to be aware of the information sources for this stage. When students arrive at the preliminary engineering stage, they define the technological solution to be used in every process step. The choice of the best-fitted technology for a given operational module is an important step. In this endeavor the students utilize all available sources of information but they have also available a schematized data bank in which the modules are categorized according to the desired action (i.e. mixing) and the various technological options available in this category are detailed. An example of such a data sheet is provided with in Appendix 2. Once the technology chosen the students proceed to the next step which consists in then modeling, optimizing and finally dimensioning the units (physical, physicochemical, chemical, biochemical or biological process units or operations). This work follows the steps depicted in the actionsflow-diagram of Appendix 3.

Over the past twelve years where this integrated approach has been adopted in the teaching of the design course, a wide range of process designs and analysis was completed. These are listed below in chronological order. A summary of the 2004 design project is given in section 5 .

1993. Design of a Kraft pulp mill to be installed at three different sites in Québec. The work was conducted in collaboration with an Engineering consulting firm, KSH in Montreal, and was awarded the first prize of the SNC Lavalin design competition of the CSChE in Calgary, Alberta, 1994.

1994. Design of a newspaper mill to be installed at three different sites in Québec. The work was also conducted in collaboration with, KSH in Montreal, and was finalist in the SNC Lavalin design competition of the CSChE held in Québec city, Québec, 1995.

1995. Design of a Kraft pulp mill using different levels of recycled pulp content to be installed at three different sites in Québec. The work was also conducted in collaboration with, KSH in Montreal.

1996. Design of a new process for the treatment of crushed electrolysis cell liners (brasques) according to the Alcan LCL\&L technology to be installed in Jonquière Québec. The work was completed in close collaboration with Alcan International and was finalist in the SNC Lavalin design competition of the CSChE held in Edmonton Alberta in 1997.

1997. Design of two different processes in collaboration with industrial partners:

- JAROFIX completed in collaboration with CEZinc Beauharnois, Québec.

- CYCLOHEXANE in collaboration with Ultramar, in Québec.

1998. Design of a Kraft pulp mills to be installed at two different sites in Québec with three different production capacities. The work was conducted in collaboration with $\mathrm{KSH}$, a consulting Engineering firm in Montreal, Québec.

1999. Design of a newspaper mill using different ratios (between 20 and $40 \%$ ) of recycled paper to be installation at two different sites in Québec with three different production capacities. The work was conducted in collaboration with $\mathrm{KSH}$, Montreal, Québec.

2000. Study of the feasibility and economic impact of design modification of two existing plants in collaboration with industrial partners. 
- Aluminum metal casting rig in collaboration with Alcan International.

- Cyclohexane production from benzene in collaboration with Ultramar, Québec.

2001. Preliminary engineering process design of a wide range of different chemical processes by smaller design groups (five to nine students).

- Ethanol production plant

- Submarine air treatment system for the removal of $\mathrm{CO}_{2}$ from breathing air. The "Neptune project"

- Sugar production from sugar cane in Jamaica

- Kraft pulp beaching using the "Xylanase" enzyme

- Oxygen delignification of Kraft pulp

- Gaseous emission cleaning from a metallurgical industry

- Plasma Assisted Oxidation of waste mud

- Hydrotreatment of gasoline

- Vinyl acetate production plant

2002. Hydrogen peroxide production plant. Project carried out in collaboration with Atofina in Bécancour Québec. The project was awarded the first prize of the SNC Lavalin design competition of the CSChE in Hamilton, Ontario, 2003.

2003. Study of the Kyoto accord and immerging business opportunities for the Canadian Chemical industry. Three possible options were studied:

- Biodiesel production plant;

- Ethanol Production plant;

- Methanol production plant.

The Biodiesel design project was awarded the second prize of the SNC Lavalin design competition of the CSChE in Calgary, Alberta, 2004.

2004. Chemical process design of four industrial approaches to the problem of solid waste recycling and/or treatment:

- Paper recycling plant;

- Urban waste incineration plant;

- Plastic waste sorting, recycling and/or gasification;

- Chemical recycling of PET.

The PET design project was submitted for this year SNC Lavalin design competition of the CSChE to be held in Toronto, Ontario 2005.

\section{An example: A summary of last year's design project}

The project was the Chemical Recycling of PET (Polyethylene Terephthalate) from the waste PET to the BHET (Bis-Hydroxy-Ethylene-Phthalate) which is the raw material for the final polymerization step to obtain virgin PET.

The output of the project is the preliminary engineering of an industrial unit able to treat up to 25000 tn of waste PET per year. The final report includes a summary of the market research, the technological survey, the strategy of control of the process, the HAZOP analysis, an environmental impact study, unit start-up procedures and protocols, maintenance operations and schedules and a detailed economic evaluation of the project including a comprehensive sensitivity analysis.

The market research examined, namely, the prospects of PET chemical recycling in order to produce BHET by glycolysis. The market trends confirm the interest of major PET producing companies to purchase BHET. To minimize costs and be able to sell the product competitively, it was determined that the eventual industrial unit should have a nominal capacity of $25000 \mathrm{tnPET} / \mathrm{year}$, and that it should be built at the state of South Carolina/USA. The technological survey takes into account the available processes for chemical recycling of PET (methanolysis; glycolysis; a combination of the previous two; neutral, acid and alkaline hydrolysis), their levels of development, the respective reaction mechanisms and conditions of operation. The gathered data have shown that glycolysis is the technological option which offers the best advantages combination from the technical, economic and environmental standpoints.

The designed manufacturing unit is made up of seven sections: Pre-treatment and conditioning of the raw material, depolymerization, separation and purification, finished products management, main utilities (raw material conditioning water loop, cooling water circuit and compressed air). The unit is almost entirely automated.

The risks analysis (HAZOP) of the process, the equipment and the various products was carried out in details. For this purpose, a list of operational modules and solutions were drawn up aiming at ensuring a safe and efficient, environmentally friendly operation of this manufacturing unit. A thorough evaluation of the environmental impacts associated the operations of this factory was carried out. The main covered points are: the forecast of the impacts generated by this type of project; the evaluation of the importance of these impacts; means allowing avoiding or attenuating the expected impacts; emissions, effluents and solid residues generated by the factory; measures necessary to be taken in order to respect the environmental standards related to the exploitation of the factory. The factory because of its geographical position must respect the standards included in Organic Chemicals and Plastics and Synthetic Fibers effluent category U.S. EPA guidelines. The respect of these standards is controlled by the Department of Health and Environmental Control of the State of South Carolina. 
The general start-up procedures were defined, and the equipment having to be connected to the generator in order to minimize the impacts at the time of a shut down of electricity, was defined. The operations of maintenance of all equipments were established according to the type of products, of the constraints of the process and of the operating conditions. These operations would take place according to the specifications related to each operational unit, preventively and in accordance with the established calendar.

The economic analysis was done after dimensioning and choosing all equipments. The costs of the equipments have been calculated either directly through requesting quotations from the manufacturers or best estimates using recent books and other literature data. The economic evaluation shows that the designed unit has an IRR of $11.4 \%$. The sensitivity analysis shows that the parameters influencing more the profitability of the unit are: the selling price of the BHET product as well as the purchase price of the residual PET. A program allowing the economic analysis as function of all influential parameters was conceived; it allowed establishing realistic scenarios according to fluctuations of the market of polymers.

\section{Summary and conclusions}

Based on our experience with the teaching of the final design course at the Universite de Sherbrooke over the past twelve years, it is safe to conclude that this course offers a great opportunity to stimulate the creativity of the students and embark them in a knowledge integration effort that is hard to match by any other classical form of teaching. The course has also been an excellent vehicle to promote their awareness to important socio-economic issues such as the Kyoto accord and solid waste recycling problems and the role the chemical engineer can play to help the society cope with such formidable problems. Through the regular meetings undertaken through out this course, the students learned also much about team effort and COMMUNICATION in all its forms; oral, written, formal and informal. The course is without doubt very demanding for the faculty members in charge; this is especially true if they set as objective to avoid going over the same terrain more than once and capture the interest and enthusiasm of the students with relevant, exciting projects that are realistic in the allowed time frame and with still limited resources.

\section{References}

[1] Peters, M.S., K.D. Timmerhaus and R.W. West, Plant Design and Economics for Chemical Engineers, Editor McGraw Hill, 2003, $5^{\text {th }}$ Edition, ISBN 0-07-239266-5.

[2] Sinnott, R.K., Coulson \& Richardson's Chemical Engineering, Editor Butterworth-Heinemann, Vol.6, $3^{\text {rd }}$ Edition, 2003, ISBN 0750641428.

[3] Seider, W.D., J.D. Seader and R.L. Lewin, Product \& Process Design Principles: Synthesis, Analysis and Evaluation, Editor Wiley, 2004, ISBN 0-471-21663-1.

[4] Ulrich, G.D. and P.T. Vasudevan, Chemical Engineering Process Design and Economics: $A$ Practical Guide, Editor Process (Ulrich) Publishing, $2^{\text {nd }}$ Edition, 2004, ISBN 0-9708768-2-3.

[5] Ray, M.S. and M.G. Sneesby, Chemical Engineering Design Project: A Case Study Approach, Gordon and Breach Science Publishers, $2^{\text {nd }}$ Edition, 1998, ISBN 905699-137-X. 


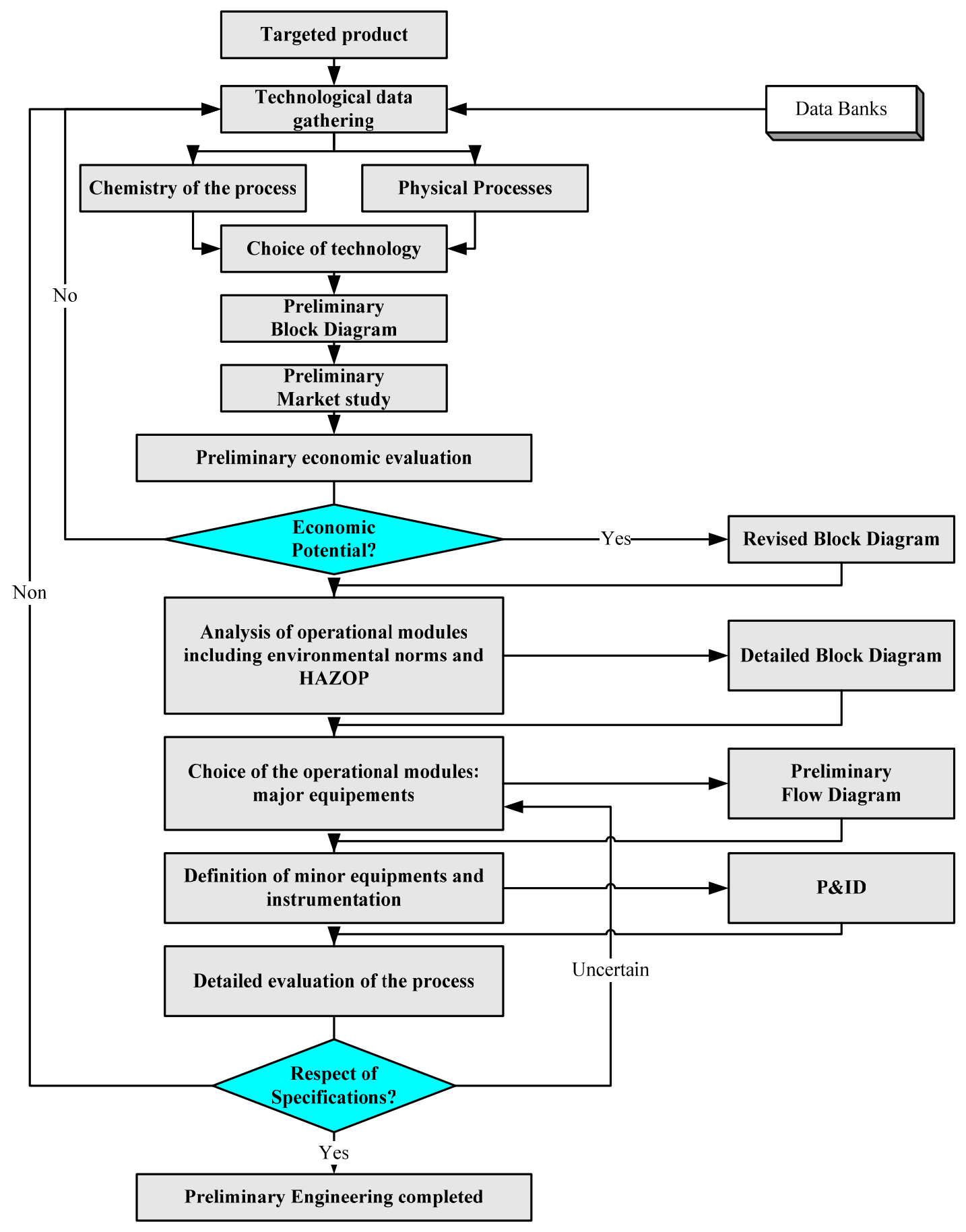

Generic steps of a design process in chemical engineering 
Appendix 2

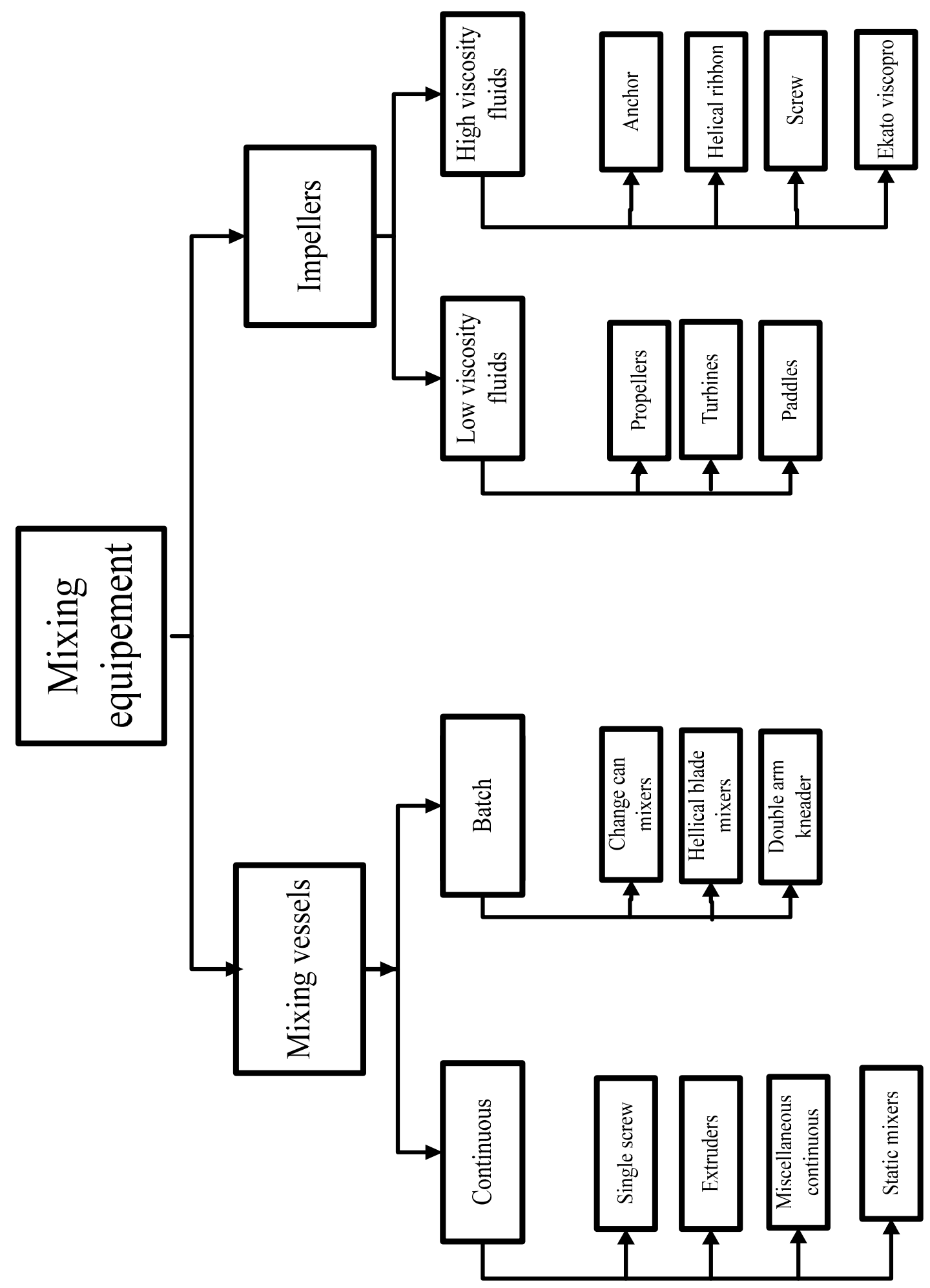

Example of the categorization of technologies in a field 


\section{Appendix 3}

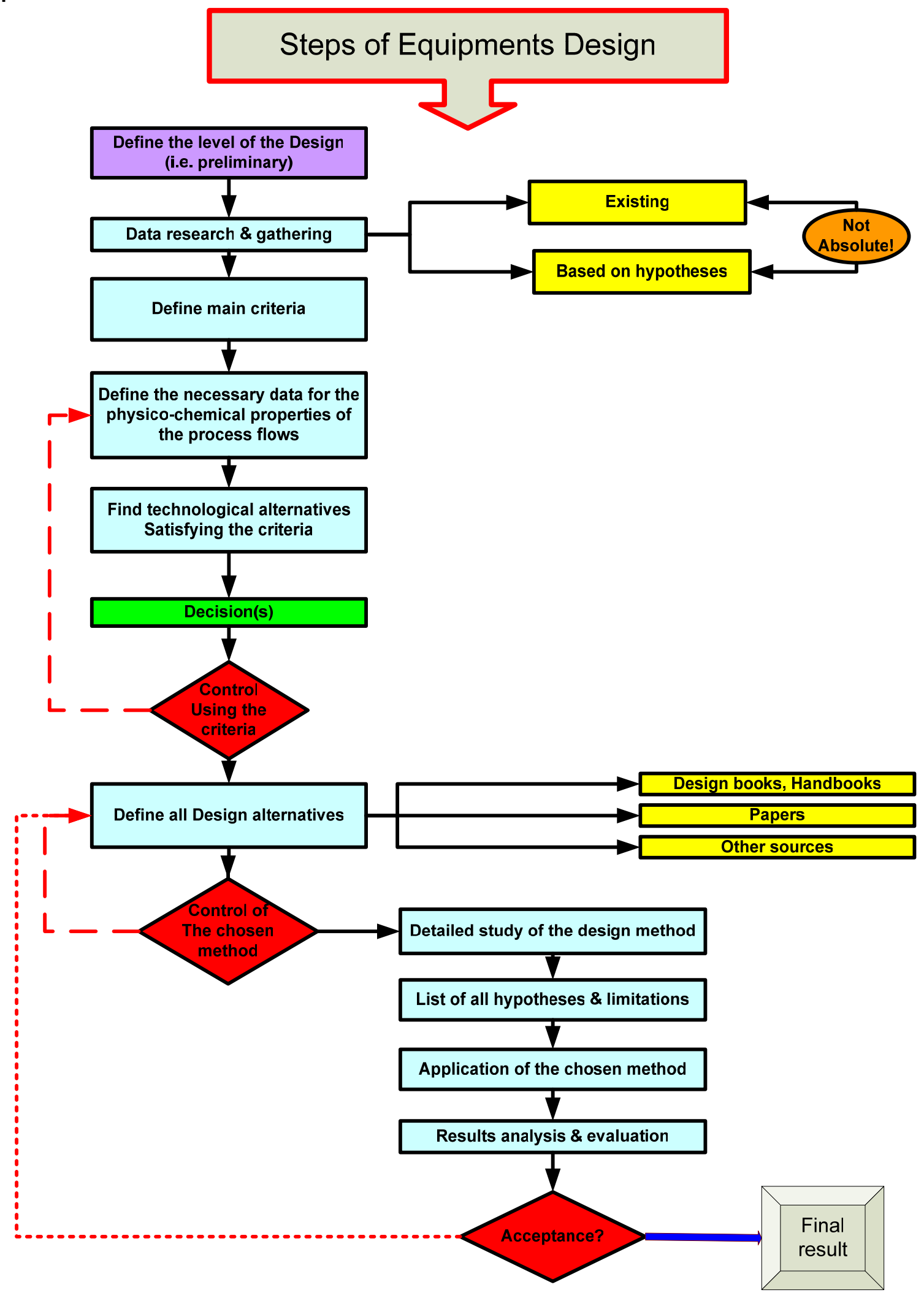

Actions-flow-diagram for an equipment design 